\title{
Effective Academic Leadership of Learning and Teaching in Malaysian Higher Education
}

\author{
Mehrnaz Fahimirad (Corresponding author) \\ Ph.D Student in Human Resource Development \\ Department of Professional Development and Continuing Education \\ Faculty of Educational Studies, University Putra Malaysia \\ E-mail: Mehrnaz.Fahimi@gmail.com
}

\begin{abstract}
Khairuddin Idris
Assistant Professor, Department of Professional Development and Continuing Education Faculty of Educational Studies, University Putra Malaysia

Sedigheh Shakib Kotamjani

PhD student in Teaching English, Department of Teaching English as Second Language

Faculty of Educational Studies, University Putra Malaysia
\end{abstract}

Received: October 14, 2016 Accepted: November 08, 2016 Published: December 01, 2016 doi:10.5296/ijhrs.v6i4.10337 URL: http://dx.doi.org/10.5296/ijhrs.v6i4.10337

\begin{abstract}
This study provides an in-depth look at the practices of leadership in selected Malaysian Universities that have been identified as academic leadership. The findings of this study support the fundamental elements that have been previously identified by researchers and professional organizations, as academic leadership. Specifically, academic leaders focus on learning and teaching for students in relation to instructor development.

This study employs a qualitative research approach. Thematic method was used to analyze the data. Data were collected through in-depth interview. Based on the findings of this study, leadership works towards the future of the university through the development and involvement of instructors to facilitate teaching and learning at Malaysian universities.
\end{abstract}


Based on the obtained results, Malaysian universities planned through sustained programs of educational development to use principles of learning and teaching effectively in designing learning environments for students. Secondly, academics need a supportive culture to put these principles into practice. To date creating learning culture depends not only on well-educated, well-meaning individual academics, but also on an academic community working together to create a student-centered attitude.

Moreover, professional development of instructors and the integrity of beliefs in pursuing organizational vision and strong professional development will support effective implementation of academic leaders' work.

Keywords: Academic leadership, Higher education, Teaching and learning

\section{Introduction}

One of the important components of an effective teaching and learning process is the presence of a strong leader (Treffinger \& Isaksen, 2005). A leader can lead a university to the success or plunge it to the pit of failure. University leaders are accountable of the fate of their institutions or organizations their powerful impact on their academic program. This significant impact may be assessed in terms of the effectiveness of the leaders in promoting and safeguarding the welfare of the different stakeholders in university.

Leadership is defined in terms of traits, characteristics and behaviors that emphasize on a clear vision, action, modeling the way, ethical relationships, congruence, trustworthiness and collaboration (Avolio \& Gardner, 2005) The nature of relationships with leaders influences job satisfaction, turnover, positive relationships and wellbeing of followers and organizational productivity (Boyatzis, R. E., Rochford, K. \& Taylor, S. N., 2015).

Leadership experiences cannot be simply categorized into transactional or transformational styles since the experiences of a leader are multidimensional and multilayered. These experiences are influenced by the sociopolitical, economic, personal and professional elements present in the lives of the leader (Day, 2001). Leadership can only be understood from the context of a leader's experiences therefore this study aims to investigate the characteristics of effective academic leadership for teaching and learning. In this context, this study sought to identify the components of effective academic leadership of teaching and learning in Malaysian Universities.

From the original idea of the university, changes and developments have deeply affected and shaped universities teaching and learning (Scott, Coates, \& Anderson, 2008a). Universities have also become more like businesses in many aspects (Gonzales, 2010). Universities are affected by external factors such as changing expectations and demands from students and stakeholders, a more globally competitive environment, higher expectations from industry, outcomes based performance, and the role of technology in changing the way teaching and learning takes place. In terms of internal factors, some self-imposed procedures complicate the delivery of teaching and learning depriving students and lecturers of needed creativity, 
flexibility, and time to optimize meaningful learning. A lack of systematic succession planning in academic leadership detracts from maintaining continuity in teaching and learning related policies and practices. All these factors contribute to the need to reconceptualize university teaching and learning.

The Malaysian government has seen it as pertinent to steer the direction of the national higher education system to ensure national interest is protected and developed in line with Vision 2020. To achieve this goal, the government has launched the National Higher Education Strategic Plan 2020 and National Higher Education Action Plan 2001-2010 as the means to transform the Malaysian higher education system consistent with the aim to raise the capacity for knowledge and innovation of the expected first-class human capital. The first phase of laying the Foundation has passed and it has entered the second phase. The second thrust of the plan, enhancing the quality of teaching and learning, is regarded as one of the key determinant factors to contribute to the transformation of higher learning institutions, especially the transformation of teaching and learning in research universities.

Higher education institutions are increasingly faced with pressures to change their practices of learning and teaching to meet the demands of industrial sectors, students, and goverment for accountability in the age of decreasing public funding (Kumar \& Kar, 2014)(Kar, Hamidifar, \& Kazerooni, 2013). In addition, universities in particular have to fulfill the pressures of meeting professional standards in relevant programmes and to use online learning to facilitate students' learning experiences. The emphasis is now on 'learning and teaching' rather than 'teaching and learning'. Therefore, full commitment to learning and teaching through the application of suitable models based on sound policies and strategies, and guided by strong academic leadership is demanded on universities to add value to students educational experiences.

In view of this situation, higher education aims to improve the practices of teaching and learning as one of the key determining factors to contribute to the transformation of the research universities and explore the factors contributing to effective academic leadership in terms of learning and teaching at universities (Jeffrey W. Alstete, 2010) (Jeffrey W. Alstete, 2010), with the emphasis on industry community engagement, character building, entrepreneurship, employability in higher education. Therefore, the purpose was to identify how academic leaders influence teachers' instructional practices; however, other factors influencing academic leadership and the development of instructors.

Similarly, the existing literature has shown that recent theoretical changes and the way that student-focused on teaching are associated with deeper methods to learning (Trigwell \& Prosser, 2004). The literature review also shows that, the way that lecturers experience the leadership of their division is an important precursor to the quality of student learning outcomes and their departmental achievement. In theory, academic leaders should consider how their leadership skills could transform an organization into meaningful change and development (Burns, 1978). To support the idea of transformational leadership another study on transformational leadership (Kalra, Pathak, \& Jena, 2013) revealed that educational leaders need to be transformational academic leaders, empowering others and enacting 
positive change within the organization.

All above leads to analyzing and determining the instructional gaps between the best practices in the structures and processes for teaching and learning of academic leadership in the public institutions of higher learning and subsequently working out the objective basis on which to improve the process. Furthermore, the concept of academic leadership has considerably been investigated in context of school in relation to the role of principal and academic leaders in terms of teaching and learning.

However, the majority of higher education research on leadership largely fail to notice the role of the academic leadership both informal; distributed leaders (Bolden, Petrov, \& Gosling, 2008) and formal leaders in universities. Taking into account that conducting research is more highly valued and rewarded in context of higher education, this gap generally might reveal the priorities of academic circles. However, the existing literature lacks attention to leading teaching and learning activities runs against to the trend of offering instructional development for academics in the world (Grant, 2009). Therefore, the role of academic leadership has not been examined in the context of higher education. This research aims to fill this gap in existing literature to examine the role of academic leaders at higher education in research universities in Malaysia. Generally, the study aims to conceptualize effective academic leadership at development of instructors in Malaysian higher education universities. Findings of this research will help MOHE to enhance the quality of leadership in learning and teaching.

\subsection{Research Questions}

This research addresses to answer the following questions:

1) What are the current practices of academic leadership in teaching and learning in selected universities?

2) What are the roles of academic leaders in facilitating learning and teaching?

\section{Academic Leadership in Learning and Teaching}

Leadership and management have been proposed as two different, but necessary, elements of formal academic governance and individuals in those roles influence the culture and learning and teaching in distinct ways (Ramsden, Prosser, Trigwell, \& Martin, 2007). Individuals with management responsibilities focus on administrative rules, tasks and functions to ensure the managerial goals of the organization are met effectively (Trigwell, Prosser, Martin, \& Ramsden, 2005). In a national study, it was shown that effective formal leaders exhibit characteristics such as self-awareness, current knowledge, competence and the ability to influence success in higher education (Scott et al., 2008a). Likewise, Bryman (2007) analyzed international literature and identified 13 forms of leader behavior associated with departmental effectiveness and concluded that leaders should focus on 'vision, integrity, consideration, and sense of direction'. Individuals in formal leadership positions who are effective demonstrate emotional intelligence and a consultative and collaborative style that supports academics to perform effectively (A Bryman, 2007). 
The recent interest in the higher education literature about leadership is in response to calls for more relevant democratic cultures and less hierarchical models of leadership (Bennett, Wise, Woods, \& Harvey, 2003). Leadership is urgently needed at all levels of the organization (Marron \& Cunniff, 2014). Distributed and collective leadership styles have been proposed as a means for academics to develop shared responsibility in changing higher education cultures (Jones, 2012). The focus of distributive leadership is on 'collective collaboration rather than individual power and control' to build leadership capacity in learning and teaching (Jones et al., 2012). There are contested meanings of leadership in higher education that need to be understood and considered in these debates, namely: 'leadership as position; leadership as performance; leadership as practice; and leadership as professional role model' (Avolio \& Gardner, 2005).

\section{Teaching and Learning in Higher Education}

Higher education faces complex managerial controls and the obligation to demonstrate relevance, accountability and benefit for society (Scott, Coates, \& Anderson, 2008b). Academics must be better prepared to provide quality learning and teaching outcomes, collaborate to identify and research real world problems, and lead the practical application of new knowledge to solve problems. But such change does not occur spontaneously in higher education - it must be led (Alan Bryman, 2007). Much of the previous research has examined the concept of formal leadership in higher education governance. Few studies have examined how academics in non-formal leadership roles understand themselves as leaders in teaching and learning in their everyday work environments to promote student experiences.

Effective leaders in higher education play a critical role in causing particular changes to occur by including people in the institutional and personal transformation and enhancement process. They assist in redesigning the operational processes of their universities so that they become less averse to changes, agile, more efficient, and more tolerant towards change.

In response to changes, a study by Scott, Coates, \& Anderson (2008) in Australia found that academic leaders need to come up not only with prompt responses to changes, but more so the responses must be of high quality that work consistently and effectively especially in the current volatile environment. Otherwise, universities will not be able to contribute to social, intellectual, cultural and human capital of the nation. In practice, Australian academic leaders were found to possess up-to-date knowledge and skills on related areas, self-aware, decisive, and committed. They are also able to empathize with and influence others, flexible and conversant with diagnostic skills and strategy formation for the organizations. Various indicators are used to judge their performance including achieving high-quality graduate outcomes, successful implementation of new initiatives, producing significant improvements in learning and teaching quality, establishing a collegial working environment, and delivering agreed tasks on time and to specification(Anderson \& Dexter, 2000).

It is undeniable that academic leaders can influence their universities and the larger society significantly in many ways, forms, direct or indirectly. At department level for instance, the key to improvement in teaching and students learning depends on the departmental leadership (Knight \& Trowler, 2000). This implied that similar outcome is expected from academic 
leadership at the higher level. In theory, academic leaders in universities would be appointed based on their background and performance in teaching and learning. Indeed, the framework as suggested by Scott, Coates, \& Anderson (2008) can become a referent point to understand the academic leadership roles and in the practices of appointing future academic leaders in teaching and learning.

Most researches in the area of teaching and learning have concentrated on two roles of leadership namely heads of department (Trowler \& Knight, 2000)(Knight \& Trowler, 2000) or department chairs (Smith \& Wolverton, 2010), specifically for creating a culture where effective teaching is rewarded and valued, and chief executives such as vice chancellors (Ferguson \& Milliman, 2008) for establishing the objectives of the university and creating the environment where improvements in teaching are welcomed (Richards, 2011).

Academic leaders have to be especially skilled at recognizing the learning programs, engagement projects, strategic developments research initiatives, approaches, structures, quality improvements, and priorities, that are aligned to their objective and that they are leveraged to continue progress in the operational context. Additionally, they have to also ensure that the changes that have been agreed on are implemented successfully and they are continuous and sustainable (Scott et al., 2008b).According to Avolio, Walumbwa, \& Weber, (2009) academic leaders' developmental requirements should be considered as the primary issue if the institutions are serious in enhancing the academic standards and quality; the universities are required to invest in developments in the academic area that allows for targeted support in particular strategic levels .Researches in Australia, New Zealand South Africa, Canada Scandinavia, Oman and South East Asia, have consistently proven that the requirements of the leaders of L \& T are practical, specific higher education and role insights into the best methods in ensuring 'good ideas' work in ways that are beneficial to students and increase the bottom line of universities (Smith \& Wolverton, 2010).

A major function of academic leadership is to have an impact on students learning and progress, and raise the standard of the teachers and staffs' performance. This can be done through increasing motivation, commitment, skills, knowledge, and working environment. A recent national study that was carried out over a period of four years showed the differences in the work, lifestyles and impact of teachers in English schools which affirms the importance of leadership along with mediating effect to commitment of teachers, effectiveness and resilience and the main function of understanding successful and effective leadership (Leithwood \& Wahlstrom, 2008). In particular, a study reflected that effective academic leaders in learning and teaching in Australia have a high knowledge and capabilities in this area. Other criteria that they possess include being self-aware, committed, decisive, empathetic and influential with a diverse group of people, flexible and skillful at analyzing and strategizing. Even though these criteria was observed across all the leaders who were researched, it was found that a more senior instructional leaders tended to show a more profound and integrated set of capabilities (Allen, 2007). Several essential roles were identifies especially for leaders in learning and teaching of higher learning institutions. The attitude, methodologies and interpersonal skills were identified to be most useful in assisting staff to change working environments were closely related to those perused by the highly 


\section{Macrothink}

International Journal of Human Resource Studies

ISSN 2162-3058

2016, Vol. 6, No. 4

effective academic lectures with their scholars. This knowledge is essential as it reveals that the most successful academic leaders both assist their staff in engaging and learning how to carry out the required changes besides establishing a supportive and efficient environment that encourages a productive learning atmosphere (Leaders \& International, 2005). Since the formal or informal aspects of engaging with others can be beneficial or detrimental to students' learning, the relationship with staff as they react and learn to reach their objectives in their job functions is equally important.

\section{Framework for Academic Leadership}

Leadership involves the exercise of influence in relation to common aims and enables people to work together to produce results they could not produce by working on their own. More precisely, effective leaders exercise reciprocal influence in order to engage people in action for common aims and mutual benefits in contingent circumstances. Consequently, many individuals are appointed to managerial roles with leadership responsibilities for establishing direction, engagement, alignment, and renewal. Effective contributions in each of these four interrelated functions are critical for growing and delivering results and innovative performance.

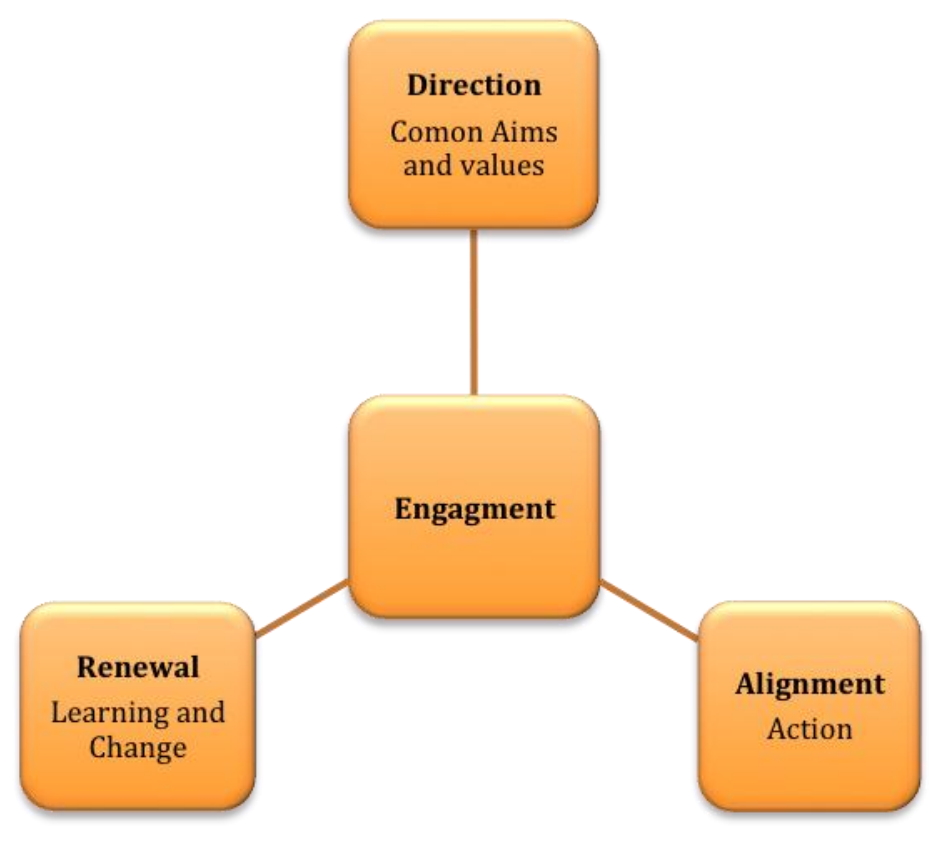

Figure 4.1 Academic Leadership Framework

Effective leaders establish common aims and shared values that engage people's motives and identity. Manifestly, fair pay and conditions that motivate matter, including meeting the basic human need to belong and identify with worthwhile aims and values.

\subsection{Direction: common aims and values}

Team members have a shared understanding of the team's agenda overall aims, values, \& strategies and how this contributes to business unit aims and values 


\subsection{Engagement: energizing. Motives and identity}

There is a high level of enthusiastic commitment to this team and to our shared responsibilities

\subsection{Alignment: coordinated agreement and action}

In this team we have clear boundaries and a clear understanding of each other's roles and responsibilities and their interdependencies. We discuss often how well we keep each other informed about activities in our respective areas of responsibility

\subsection{Renewal: learning and change}

We review regularly the way we coordinate information, decisions and activities in relation to the team's agenda aims, values, and strategies and how this contributes to business unit aims and values. We develop and implement ideas for new and improved ways of progressing the team's agenda in the context of business unit aims and values.

\section{Methodology}

Qualitative approach was utilized in this research. Selected academic leaders in learning and teaching in public and private universities in Malaysia involved in this study. For the qualitative approach data were gathered from:

a. Documentary analysis on universities' strategic plans and materials pertinent to universities' academic policies;

b. Structured interview was sent to deputy deans (academic affairs) and head departments to gauge their perceptions on academic leadership practices in learning and teaching in the universities.

The participants of this study involved the academic leaders as well as the development of instructors in Malaysian research universities namely UM, UPM,UTM, UKM, USM. Semi-structured interviews were conducted with the Deputy Vice-Chancellors / Deputy rectors in charge of learning and teaching from the research universities of Malaysia. Moreover, the strategic plans, materials, and documents related to the academic policies of universities were analysed. Furthermore, personal and in-depth account of academic leaders past experiences justifies the researcher's preference for using interviewing instead of questionnaires in the study. The researcher initially constructed the interview protocol questions based on the review of the relevant literature, which included books, journals, and other related materials. The interview schedule was used to obtain relevant information from the leaders. The interview protocol contained questions on the professors' academic and career histories, significant events, experiences and related factors that they believe are related to their academic socialization. Data collection in this study sought to provide rich descriptive data that would identify and describe the academic leadership behaviors that positively influence on teaching and learning and the organizational capacity and coherence of universities to support the development of instructors. Leaders from targeted universities served as the primary units of analysis. 


\subsection{Data Analysis}

Data analysis in this study was implemented through two strategies. The study of the material culture (Marshall \& Rossman, 1999) of the universities included a review of relevant documents and the identification and observation of artifacts. Artifacts, "the entities designed to shape and enable organizational practices," (Harris, Leithwood, Day, Sammons, \& Hopkins, 2007). The second strategy utilized for data collection in this study was interviews. Interviews were conducted individually with academic leaders. The multiple points of information served to triangulate data (Creswell \& Miller, 2000)\&(Maxwell, 2004) and subsequently prevented the researcher from accepting initial impressions of collected data.

A system of color-coding datum was utilized to code sources of data and subcategories were labeled in the margin of sources. Throughout the coding process, it was clear that overlap between the work of the leaders and the leadership of academic leader exists (Glaser, 2013). At times the overlap was significant enough that it could not be avoided and the datum was subsequently dually coded. The categories that make up the typology were used to organize the final report. The data for each interview were re-coded as themes emerged within each of the broader categories.

All themes and their corresponding data points were catalogued into a single data summary document (Collins, 2003). Unrelated themes that emerged during the analysis process were not automatically discounted and contributed to the subsequent cross-data analysis. The final level of analysis was a cross-data analysis that is framed by the questions posed in this study. Single cases were compared to find consistencies and differences across data. The goal of this process was to develop general answers to the research questions (Hughes, 2005). All research questions and their corresponding data points were catalogued into a single data summary document.

\section{Finding and Discussion}

To answer the first research question regarding the current practices of leadership in teaching and learning in Malaysian Research Universities, thematic analysis was used. Based on the in-depth interviews, the findings are as follows:

1) The first research question addresses the current practices of leadership in teaching and learning in research universities. The first sub theme among interviews and document analysis was recognized as vision driven for learning and teaching. Instructors, who focus on learning directly and indirectly, have powerful influences on students' achievement through the development of a strong culture on students learning. Academic leaders highlighted the importance of learning and teaching in order to attract a new generation of leaders to this critical role as the current effective leadership of learning and teaching in universities to the individuals, surrounding communities and country (Trigwell \& Prosser, 2004). Academic leaders have a strong commitment to pedagogy, research and development should be driven by a strong grasp of how learning occurs and the effects of different forms of teaching on student learning. Furthermore, they must be aware of knowledge of the curriculum areas and factors, which need to be considered when designing relevant and effective curricula. They 
also emphasize on students' acheivement, instructional practice, maintaining faculty environment to support learning, clear communication that learning is the priority of the university. In addition, this study has found that the process of developing a community that is unified around one vision for faculties is one of aspect of culture building that has resulted in a sense of shared ownership to improve initiatives at university. Developing strong vision and mission statements can help stakeholders in each university to reach to such a common understanding(Scott et al., 2008b).

The second common sub-theme related to best practices of academic leaders, is identified as creating an environment for academic achievement; leaders to teachers and students directly and indirectly communicate high expectations for student learning and instruction. The direct communication of leader's expectations takes the form of an explicit articulation of academic benchmarks to staff and verbal and written communication regarding student achievement report. Indirect communication of the leader's expectations is seen through communicating students with teachers via given academic benchmarks at the faculties, which are initiated and supported by academic leaders. Therefore, increased student achievement is one indicator of academic leadership. It is clear that there is connection between leaders and the members of the faculty community to facilitate a university environment that makes the realization of those expectations possible. Academic leaders in the interview believed that strong teacher professional communities, and collective work on improving instruction are key factors for raising achievement. According to interviews academic leaders with their leadership teams in research universities are committed to distributed leadership and a focus on instruction to bring about deep student learning and high levels of student achievement. These teams were given the permission to design and propose a curriculum that aligned roles, responsibilities, leadership practices, instruction and school culture to a focus on increased student achievement and the establishment of an effective university environment.

2) Leaders 'interpersonal capabilities, academic leaders evaluate followers, one to one instructional coaching, and leaders with the faculties and executive team to get the right people and investigate factors that hinder academic leaders 'capability. The study has validated the key capabilities that were statistically identified in previous studies, which retained their importance across all of the leadership roles.

In the first sub-theme of capabilities, interpersonal capabilities have been identified as a vital factor in communicating academic leaders with staff. It has been revealed the crucial role of interpersonal in effective leadership for learning and teaching.

Likewise, other previous studies in the area of higher education have comparably highlighted the importance of academic relationship in effective leadership. For instance according to (Smith \& Wolverton, 2010) leaders are those who have ability to resolve the tensions efficiently and effectively in the process of adapting". The ability to listen and respond suitably to other staff and understand social dynamics play a major role in aspect of the "community building" (Osborn, Hunt, \& Jauch, 2002). In the same way, (Yusnita, Amin, \& Muda, 2012) analyzed the components of leadership identified the ability of leader who has the capacity to sustain the faculty's morale and to resolve, reduce, and to avoid conflict 
among faculty members. Blom \& Alvesson, (2014) in his study concentrated on the social and personal aspects of leadership and emphasized the importance of emotional intelligence.

Furthermore, one of the most important capability of leaders is coordinating and aligning the university's work vertically for curriculum development implementation and enhancement so the primary role is to serve as a department chair leading meetings every two weeks/monthly, focused on curriculum planning, "supporting" team members, observing team members quarterly in the classroom and providing formative feedback.

This study reveals the necessary responsibility of academic leader is to observe and evaluate instructors, coaching, and general administrative duties. Academic leaders also attend to a myriad of administrative duties and tasks. The instructional support team coordinates the efforts of the content area departments, aligning the university's work vertically for curriculum development, implementation and enhancement. The advisory teams organize the work horizontally, focusing on a particular group of students and their needs. This team meets every month for three hours. The next finding is related to capability of academic leaders at research universities, is to get or hire the right people. They mentioned that the employment of qualified people on research universities has contributed to the development of a professional community that is unified around one vision and one mission of research universities.

To end, some factors hinder academic leaders to improve the quality of instruction at higher education, this study found several reasons that academic leaders confront with them while working at universities. First time second resources and lack of willingness to have difficult conversations. Both time and resources hinder the ability to improve instruction. This is most directly a result of having a lack of planned time to meet and discuss instruction and curriculum with staff members.

3) The last finding of this study is related to professional development of instructors. The finding has been revealed that the Malaysian government annually invests a large proportion of its income on education in both infrastructure and provision sectors and human resource development.

Professional development of instructors and the integrity of beliefs in pursuing organizational vision and strong professional development will support effective implementation of academic leaders' work. This function is realized through the academic leaders focus on the success of university (rather than her own self-interest), on his/her being willing to do whatever it takes to achieve the mission of the university, and on her/his ability to get the right people working at the university. Academic leaders made an attempt to get the right people through the deliberate use of shared leadership and the development of a nurturing relationship with staff. According to existing literature (Afshari, Bakar, \& Luan, 2008) student-centered approaches have been employed by Malaysian teacher education to facilitate learning in the Malaysian teacher education programs. These approaches make student to take more responsibility to actively engage in learning and to promote them to involve and participate in the learning process. According to interview with academic leaders in Malaysian research universities academic leaders play an important role to conceptualize the 
learning and teaching functions in higher education institutions.

As a preliminary report summarized several conceptualizations related to learning and teaching mission:

The mission of these universities is to become top employer, top choice university. These universities will be renowned for producing students that will meet the standard set by employers. For every discipline, they have identified the top employers. High percentage of students does internship and eventually get job in these top companies. One of the academic leaders explicitly mentioned that "Our mission is to make our students marketable in the market world. It is to make them industrially ready to get specified job. All programmes as well as learning and teaching goals are geared to fulfil our mission".

According to Goleman, (2013) "Teacher development is defined as professional growth a teacher achieved as a result of gaining experience and evaluating his or her teaching systematically". These professional developments can be achieved through gaining experiences for instance mentoring, participating in workshops or professional development meetings, or obtaining informal experiences by means of reading books, watching program in regard to any academic subjects (Goleman, 2013).

To answer the second research question regarding the roles of academic leaders the findings were categorized under three categories: organizational demands, interpersonal demands and intrapersonal demands. Interwoven in each of these categories are the themes of functions, attributes and challenges of academic leadership.

The analysis of documents describing the role and responsibilities of academic leaders in the five institutions that participated in the study reveals that there is considerable similarity in the way the multi-dimensional role and its functions are communicated. Common elements have been clustered below under the roles of organizational leadership, curriculum leadership, academic management and academic currency, which appear to be the dominant facets of the academic leadership role descriptions in these universities:

1) Organizational leadership:

- Setting direction and planning for the unit that meshes with the institution's vision/strategy;

- Contributing to academic decision making (e.g. Member of Academic Board);

- Interaction with other departments and services to advance the department/ program; and

- Compliance with national and institutional policy and objectives (such as Treaty of Waitangi objectives).

2) Curriculum leadership:

- Setting direction for program areas;

- Leading continuous improvement in academic activities; 
- Creating a research culture (degree programs);

- Managing quality assurance processes (assessment, reporting, curriculum design, review and development);

- Managing alumni and external stakeholder engagement; Marketing and promoting programs.

3) Academic management:

- Managing staff appointments, performance and development;

- Managing budgets;

- Securing external research/consultancy revenue;

- Managing the teaching and learning environment; and

- Managing serious student issues.

4) Academic currency:

- Maintaining teaching and research involvement

- Maintaining a publishing profile (negotiable); and

- Developing self.

Invariably, the documentation also refers to key attributes that the institutions are seeking in relation to academic leadership effectiveness. The following appear consistently in the data referring to competencies and qualities expected of heads of department and programs:

. Ability to communicate effectively;

. Ability to motivate staff and treat them fairly;

. Ability to involve staff appropriately in decision making (collaborate effectively);

. Ability to act as a role model (for ethical behavior; for teaching excellence; for teamwork)

. Ability to lead/inspire a team;

. Have academic credibility (a postgraduate qualification sometimes specified); and

. Have highly developed interpersonal and relational skills.

These data contained in the role-associated documents relate closely to the three categories of organizational, interpersonal and intrapersonal demands that are used to analyze the interview data.

\section{Conclusion}

This study has undertaken to illuminate the roles and practices of academic leader and the development of instructors at Malaysian research universities. The first research question addresses the practices of academic leaders at research universities. 
Academic leaders articulate and explain the vision and mission of the university; to develop the future of community and build the culture of shared ownership among instructors and staff. Developing strong vision and mission statements can help instructors and staff in each university to reach to such a common understanding.

Leadership works towards the future of the university through the development and involvement of instructors to facilitate teaching and learning at research universities. Academic leadership places a very important role in the function of teaching and learning in research universities. Malaysian research universities planned through continuous programs for educational development in order to connect theory with practice, instructors are supposed to learn using these principles efficiently to design appropriate learning environments for students (Fry, Ketteridge, \& Marshall, 2009). Secondly, instructors require a supportive culture if they intend to apply these principles into practice. Furthermore, creating a supportive learning culture is determined by well-educated, and also determined by academic community working collectively to generate a student-centered attitude (Marginson, 2013). To do so, sound academic leadership is required. Moreover, academic leaders at Malaysian research universities cultivate communication throughout the organization through team building. Another responsibility of academic leaders is to recruit appropriate people at university.

Professional development practices are grounded in the beliefs of academic leadership. Professional development of instructors and the integrity of beliefs in pursuing organizational vision and strong professional development will support effective implementation of academic leaders' work. This function is realized through the academic leaders focus on the success of university to achieve the mission of the university. Academic leaders provide opportunity for professional develoment of instructors at higher education.

\section{References}

Afshari, M., Bakar, K., \& Luan, W. (2008). School leadership and information communication technology. Turkish Online Journal of ..., 7(4), 82-91. Retrieved from http://tojet.net/articles/v7i4/749.pdf

Allen, S. J. (2007). Adult Learning Theory \& Leadership Development. Leadership Review Claremont McKenna College Kravis Leadership Institute, Leadership Review, 7(7), 26-37.

Anderson, R., \& Dexter, S. (2000). School technology leadership: Incidence and impact. IT in Education.

Avolio, B. J., \& Gardner, W. L. (2005). Authentic leadership development: Getting to the root of positive forms of leadership. Leadership Quarterly. http://doi.org/10.1016/j.leaqua.2005.03.001

Avolio, B. J., Walumbwa, F. O., \& Weber, T. J. (2009). Leadership: current theories, research, and future directions. Annual Review of Psychology, 60, 421-449. http://doi.org/10.1146/annurev.psych.60.110707.163621 


\section{Macrothink}

International Journal of Human Resource Studies ISSN 2162-3058 2016, Vol. 6, No. 4

Bennett, N., Wise, C., Woods, P., \& Harvey, J. (2003). Distributed Leadership : A Review of Literature Distributed Leadership. National College for School Leadership.

Blom, M., \& Alvesson, M. (2014). Leadership On Demand: Followers as initiators and inhibitors of managerial leadership. Scandinavian Journal of Management, 30(3), 344-357. http://doi.org/10.1016/j.scaman.2013.10.006

Bolden, R., Petrov, G., \& Gosling, J. (2008). Tensions in higher education leadership: Towards a multi-level model of leadership practice. Higher Education Quarterly, 62(4), 358-376. http://doi.org/10.1111/j.1468-2273.2008.00398.x

Boyatzis, R. E., Rochford, K. \& Taylor, S. N. (2015). The role of the positive emotional attractor in vision and shared vision: toward effective leadership, relationships, and engagement. Frontiers in Psychology, 6(May), 670. http://doi.org/10.3389/fpsyg.2015.00670

Bryman, A. (2007). Effective leadership in higher education: a literature review. Studies in Higher Education, 32(6), 693-710. http://doi.org/10.1080/03075070701685114

Bryman, A. (2007). Effective leadership in higher education: a literature review. Studies in Higher Education. http://doi.org/10.1080/03075070701685114

Burns, J. M. (1978). Leadership. Oxford.

Collins, D. B. (2003). The effectiveness of managerial leadership development programs: A meta-analysis of studies from 1982--2001. Dissertation Abstracts International Section A: Humanities and Social Sciences, 63(8-A), 2929.

Creswell, J. W., \& Miller, D. L. (2000). Determining Validity in Qualitative Inquiry. Theory into Practice, 39(3), 124-130. http://doi.org/10.1207/s15430421tip3903

Day, D. V. (The P. S. U. (2001). Leadership development:A review in context. The Leadership Quarterly. http://doi.org/10.1016/S1048-9843(00)00061-8

Ferguson, J., \& Milliman, J. (2008). Creating Effective Core Organizational Values: A Spiritual Leadership Approach. International Journal of Public Administration, 31(4), 439-459. http://doi.org/10.1080/01900690701590835

Fry, H., Ketteridge, S., \& Marshall, S. (2009). A Handbook for Teaching and Learning in Higher Education. A Handbook for Teaching and Learning in Higher Education. http://doi.org/10.1080/03075079312331382498

Glaser, B. (2013). Grounded theory methodology. Introducing Qualitative Research in Psychology, 69-82.

Goleman, D. (2013). The focused leader. Harvard Business Review, (DEC).

Gonzales, A. (2010). National Union Catalog of Manuscript Collections (NUCMC). Cataloging \& Classification Quarterly, 48(2-3), 187-193. http://doi.org/10.1080/01639370903535700

Grant, J. (2009). Theory and Practice in Planning the Suburbs: Challenges to Implementing 
New Urbanism, Smart Growth, and Sustainability Principles. Planning Theory \& Practice, 10(1), 11-33. http://doi.org/10.1080/14649350802661683

Harris, a, Leithwood, K., Day, C., Sammons, P., \& Hopkins, D. (2007). Distributed leadership and organizational change: Reviewing the evidence. Journal of Educational Change, 8, 337-347. http://doi.org/10.1007/s10833-007-9048-4

Hughes, J. (2005). The role of teacher knowledge and learning experiences in forming technology-integrated pedagogy. Journal of Technology and Teacher Education, 13(2), 277 302. http://doi.org/http://www.editlib.org/p/26105

Jeffrey W. Alstete. (2010). Policy and Performance in American Higher Education: An Examination of Cases across State Systems (review). The Review of Higher Education. http://doi.org/10.1353/rhe.2010.0014

Jones, D. (2012). Servant Leadership's Impact on Profit, Employee Satisfaction, and Empowerment Within the Framework of a Participative Culture in Business. Business Studies Journal, 4(1), 35-49.

Kalra, S., Pathak, V., \& Jena, B. (2013). Qualitative research. Perspectives in Clinical Research, 4(3), 192. http://doi.org/10.4103/2229-3485.115389

Kar, N. C., Hamidifar, S., \& Kazerooni, M. (2013). Analytical modelling and parametric sensitivity analysis for the PMSM steady-state performance prediction. IET Electric Power Applications, 7(7), 586-596. http://doi.org/10.1049/iet-epa.2011.0281

Knight, P. T., \& Trowler, P. R. (2000). Department-level cultures and the improvement of learning and teaching. Studies in Higher Education, 25(1), 69-83. http://doi.org/10.1080/030750700116028

Kumar, P., \& Kar, M. (2014). Effect of structural transition on magnetic and optical properties of $\mathrm{Ca}$ and $\mathrm{Ti}$ co-substituted $\mathrm{BiFeO} 3$ ceramics. Journal of Alloys and Compounds, 584, 566-572. http://doi.org/10.1016/j.jallcom.2013.09.107

Leaders, D. F., \& International, R. H. R. (2005). Leadership succession planning "affects commercial success": Chief executives crucial to developing high-potential employees. Human Resource Management International Digest, 13(1), 36-38. http://doi.org/10.1108/09670730510576419

Leithwood, K., \& Wahlstrom, K. L. (2008). Linking Leadership to Student Learning: Introduction. Educational Administration Quarterly, 44(4), 455-457. http://doi.org/10.1177/0013161X08321495

Marginson, S. (2013). The impossibility of capitalist markets in higher education. Journal of Education Policy, 28(3), 353-370. http://doi.org/10.1080/02680939.2012.747109

Marshall, C., \& Rossman, G. (1999). Building the conceptual framework. Designing Qualitative Research (3rd Edition).

Maxwell. (2004). Conceptual Framework. Journal of Educational Administration, 30(4), 
33-64. http://doi.org/10.1186/1472-6963-11-23

Osborn, R. N., Hunt, J. G., \& Jauch, L. R. (2002). Toward a contextual theory of leadership. Leadership Quarterly, 13(6), 797-837. http://doi.org/10.1016/S1048-9843(02)00154-6

Ramsden, P., Prosser, M., Trigwell, K., \& Martin, E. (2007). University teachers' experiences of academic leadership and their approaches to teaching. Learning and Instruction, 17(2), 140-155. http://doi.org/10.1016/j.learninstruc.2007.01.004

Richards, D. (2011). Leadership for Learning in Higher Education: The Student Perspective. Educational Management Administration \& Leadership, 40(1), 84-108. http://doi.org/10.1177/1741143211420617

Scott, G., Coates, H., \& Anderson, M. (2008a). Learning Leaders. Acer, (May).

Scott, G., Coates, H., \& Anderson, M. (2008b). Learning leadership in times of change: Academic Leadership Capabilities for Australian Higher Education. Higher Education Research.

Smith, Z. a., \& Wolverton, M. (2010). Higher Education Leadership Competencies: Quantitatively Refining a Qualitative Model. Journal of Leadership \& Organizational Studies, 17(1), 61-70. http://doi.org/10.1177/1548051809348018

Treffinger, D. J., \& Isaksen, S. G. (2005). Creative problem solving: The history, development, and implications for gifted education and talent development. Gifted Child Quarterly, 49(4), 342-353. http://doi.org/10.1177/001698620504900407

Trigwell, K., \& Prosser, M. (2004). Development and use of the approaches to teaching inventory. Educational Psychology Review, 16(4), 409-424. http://doi.org/10.1007/s10648-004-0007-9

Trigwell, K., Prosser, M., Martin, E., \& Ramsden, P. (2005). University teachers' experiences of change in their understanding of the subject matter they have taught. Teaching in Higher Education, 10(2), 251-264. http://doi.org/10.1080/1356251042000337981

Trowler, P., \& Knight, P. T. (2000). Coming to Know in Higher Education: Theorising faculty entry to new work contexts. Higher Education Research \& Development, 19(1), 27-42. http://doi.org/10.1080/07294360050020453

Yusnita, Y., Amin, A., \& Muda, S. (2012). The Influences of Transformational Leadership in Homestay Programme. The International Journal of Social Sciences, 1(1), 1-7.

\section{Copyright Disclaimer}

Copyright for this article is retained by the author(s), with first publication rights granted to the journal.

This is an open-access article distributed under the terms and conditions of the Creative Commons Attribution license (http://creativecommons.org/licenses/by/3.0/). 